\title{
Pacemaker implantation complication rates in elderly and young patients
}

\author{
This article was published in the following Dove Press journal: \\ Clinical Interventions in Aging \\ 6 August 2013 \\ Number of times this article has been viewed
}

\section{Kazım Serhan Özcan \\ Damirbek Osmonov \\ Servet Altay \\ Cevdet Dönmez \\ Ersin Yıldırım \\ Ceyhan Türkkan \\ Barıș Güngör \\ Ahmet Ekmekçi \\ Ahmet Taha Alper \\ Kadir Gürkan \\ İzet Erdinler}

Department of Cardiology, Siyami Ersek Cardiovascular and Thoracic Surgery Center, Istanbul, Turkey
Correspondence: Kazım Serhan Özcan Barbaros Mahallesi, Bekir Sıtkı Sezgin Sokak, Özlem Sitesi, B blok, Daire: 9 Üsküdar, Koșuyolu-İstanbul, 34087, Turkey

Tel +90 5326742429 ;

+902165454736

Fax +902163379719

Email serhandr@gmail.com; serhan_oz@yahoo.com
Aims: To evaluate the complication rate differences between elderly and younger patients who receive a permanent pacemaker implantation.

Methods: We reviewed all cases admitted to our institution between January 2008 and June 2009 with symptomatic bradyarrhythmia for whom a permanent pacemaker was implanted. Beginning in June 2009, we prospectively collected data from all patients with the same diagnosis and procedure. The frequency of complications due to the pacemaker implantation procedure was evaluated and compared between young ( $<70$ years old) and elderly ( $\geq 70$ years old) patients.

Results: Among 574 patients with a permanent pacemaker, 259 patients $(45.1 \%)$ were below and 315 patients (54.9\%) were above or at 70 years of age. There were $240(92.7 \%)$ and $19(7.3 \%)$ dual-chamber pacemaker (DDD) and single-chamber pacemaker (VVI) implanted patients in the younger group, and 291 (76.8\%) and 73 (23.2\%) DDD and VVI pacemaker implanted patients in the elderly group, respectively. The complication rate was 39 (15.1\%) out of 259 young patients and $24(7.6 \%)$ out of 315 elderly patients. Postprocedural complications were statistically lower in the elderly patients than in younger patients $(P=0.005)$.

Conclusion: A pacemaker implantation performed by an experienced operator is a safe procedure for patients of advanced age. The patients who are above 70 years old may have less complication rates than the younger patients.

Keywords: complications of pacemaker implantation, elderly patients, permanent pacemaker

\section{Introduction}

Pacemaker implantation is performed for patients of all ages with bradyarrhythmias but especially in the elderly population. ${ }^{1,2}$ According to earlier reports, approximately $70 \%$ to $80 \%$ of all pacemaker implantations are done to patients who are or above 65 years old. ${ }^{3}$ Physicians usually believe that older patients who need a permanent pacemaker implantation may have higher postprocedural complication rates than younger ones. In the present study, we report our experience of pacemaker implantation complications between elderly and younger patients beginning from January 2008 to December 2010.

\section{Methods}

We reviewed all cases admitted to our institution between January 2008 and June 2009 with a diagnosis of symptomatic second degree or third degree atrioventricular (AV) block, 2:1 AV block, atrial fibrillation (AF) with bradycardia (average heart 
rate $\leq 40$ beats per minute on 24-hour Holter monitoring) for whom a permanent pacemaker was implanted. We also prospectively collected data from all patients with the same diagnosis criteria and procedure beginning from June 2009 until December 2010. Type of bradyarrhythmia was defined by surface electrocardiography. A permanent pacemaker was implanted by an experienced operator who had performed $>300$ procedures in all and who performs $>150$ procedures a year. Pacemaker types were chosen according to the type of bradyarrhythmia, patient's age, physical status, and mobility state. The cardiac device implantations were performed according to the standard technique described in the literature. ${ }^{4-6}$ All patients who used oral anticoagulants for previous indications ceased warfarin therapy and administered enoxaparin, as a bridging therapy, before the procedure.

The study group consisted of 574 patients. Patients who were $\geq 70$ years old were classified as elderly patients and the rest of the patients were classified as young patients. Patients were discharged from hospital at least 48 hours after the procedure and were followed in an outpatient service at the first week, first month, third month, and every six months. Postprocedural complications were defined when pocket hematoma requiring a drainage, local pacemaker area infection, lead infection, lead dislodgement/dysfunction, pocket fibrosis, pneumothorax, and myocardial rupture were diagnosed. The frequency of complications due to the pacemaker implantation procedure was evaluated and compared between young and elderly patients.

\section{Statistical analysis}

Quantitative variables were expressed as mean value \pm standard deviation, and qualitative variables were expressed as a percentage. Categorical data were compared using the Pearson Chi-square test. A $P$-value $<0.05$ was considered statistically significant. All statistical studies were carried out using Number Crunchers' Statistical System 2007 and Power Analysis and Sample Size 2008 Statistical Software program (NCSS LLC, Kaysville, Utah, USA).

\section{Results}

We have evaluated 574 patients who received a permanent pacemaker implantation. Baseline demographics and clinical characteristics of patients are demonstrated in Table 1. The number of patients in the elderly group was 315 . There were 154 men (48.9\%) and 161 women $(51.1 \%)$ and their ages ranged from 70 to 93 years with a mean age of $78.4 \pm 5.8$ years. Of these patients, 216 (68.6\%) had complete AV block,
Table I Baseline demographics and clinical characteristics

\begin{tabular}{|c|c|c|c|}
\hline & $\begin{array}{l}\text { Age }<70 \text { years } \\
(n=259)\end{array}$ & $\begin{array}{l}\text { Age } \geq 70 \text { years } \\
(n=315)\end{array}$ & $P$-value \\
\hline Male gender & $130(50.2 \%)$ & I54 (48.9\%) & 0.75 \\
\hline Hypertension & $109(42 \%)$ & $186(59 \%)$ & 0.01 \\
\hline Diabetes mellitus & 91 (35\%) & $120(38 \%)$ & 0.46 \\
\hline Chronic renal failure & $16(6 \%)$ & $32(10 \%)$ & 0.09 \\
\hline COPD & 44 (16\%) & 59 (I8\%) & 0.59 \\
\hline Body weight, kg & $79.6 \pm 9.3$ & $77.5 \pm 8.3$ & 0.01 \\
\hline \multicolumn{4}{|l|}{ ECG findings } \\
\hline Complete AV block & 154 (59.5\%) & $216(68.6 \%)$ & 0.19 \\
\hline Second degree & $48(18.5 \%)$ & 47 (I4.9\%) & 0.49 \\
\hline \multicolumn{4}{|l|}{ AV block } \\
\hline $\mathrm{AF}$ and bradycardia & 14 (5.4\%) & I5 (4.8\%) & 0.85 \\
\hline Sick Sinus Syndrome & $23(8.9 \%)$ & $16(5.1 \%)$ & 0.30 \\
\hline Sinusal pause & $8(3.1 \%)$ & II (3.5\%) & 0.88 \\
\hline Advanced AV block & $5(1.9 \%)$ & $4(1.3 \%)$ & 0.77 \\
\hline Trifascicular block & I $(0.4 \%)$ & $4(1.3 \%)$ & 0.26 \\
\hline Nodal rhythm & $6(2.3 \%)$ & $2(0.6 \%)$ & 0.10 \\
\hline \multicolumn{4}{|l|}{ Pacemaker type } \\
\hline DDD & $240(92.7 \%)$ & 242 (76.8\%) & 0.01 \\
\hline VVI & $19(7.3 \%)$ & $73(23.2 \%)$ & \\
\hline
\end{tabular}

Abbreviations: AF, atrial fibrillation; $\mathrm{AV}$, atrioventricular; $\mathrm{COPD}$, chronic obstructive pulmonary disease; DDD, dual chamber pacemaker; ECG, electrocardiogram; $\mathrm{VVI}$, single chamber pacemaker.

47 (14.9\%) had second degree AV block, 15 (4.8\%) had AF with slow ventricular response, 16 (5.1\%) had Sick Sinus Syndrome, 11 (3.5\%) had sinus pause, and eight (3.2\%) had other bradyarrhythmias. While 242 patients $(76.8 \%)$ received a dual-chamber pacemaker (DDD), the rest of the patients $(23.2 \%)$ received a single-chamber pacemaker (VVI) implantation. Elderly people had a significantly higher rate of hypertension and the body weight was significantly lower than their younger counterparts.

The number of patients in the young patients group was 259. There were 130 men (50.2\%) and 129 women (49.8\%) and their ages ranged from 12 to 69 years with a mean age of $54.7 \pm 14$ years. Of these patients, 154 (59.5\%) had complete AV block, 48 (18.5\%) had second degree AV block, 14 (5.4\%) had AF with slow ventricular response, 23 (8.9\%) had Sick Sinus Syndrome, eight (3.1\%) had sinus pause, and $12(4.6 \%)$ had other bradyarrhythmias. Two hundred and forty patients $(92.7 \%)$ received a DDD pacemaker and 19 patients $(7.3 \%)$ received a VVI pacemaker implantation.

The complication rate was $24(7.6 \%)$ out of 315 in the elderly patients and $39(15.1 \%)$ out of 259 in the young patients. Postprocedural complications were statistically lower in the elderly patients than in the younger patients $(P=0.005)$ (Table 2$)$. Mean follow-up time was $14 \pm 2.1$ months for elderly people and $15 \pm 1.8$ months for younger patients $(P>0.05)$. 
Table 2 Complication rates

\begin{tabular}{llll}
\hline Complication & Age & P-value \\
\cline { 2 - 3 } & $<\mathbf{7 0}$ years & $\geq \mathbf{7 0}$ years & \\
\hline Yes & $39(15.1 \%)$ & $24(7.6 \%)$ & \\
No & $220(84.9 \%)$ & $291(92.4 \%)$ & 0.005 \\
Total & 259 & 315 & \\
\hline
\end{tabular}

The most common complication of the elderly patients was pocket hematoma (nine events in seven patients) followed by infection of the pocket (seven events in five patients), pneumothorax (four patients), lead dislodgement/dysfunction (four patients), pocket fibrosis (three patients), and myocardial rupture (one patient). In young patients, the most common complication was pocket hematoma (13 patients) followed by lead dislodgement/dysfunction (eleven patients), infection of the pocket (seven patients), lead endocarditis (six patients), and pneumothorax (two patients) (Table 3).

\section{Discussion}

Permanent pacemaker implantation is reported to be high in older people. ${ }^{1,7}$ It is shown to be a feasible treatment option in elderly patients with symptomatic bradyarrhythmias who have a life expectancy of more than 8 years. ${ }^{89}$ Generally, physicians and surgeons prejudge that these patients who need permanent pacemaker implantation may have higher complication rates due to their comorbidities. ${ }^{10}$ However, in the literature, elderly patients are shown to have similar complication rates to younger ones. ${ }^{11}$ In a previous study by Link et al, ${ }^{11}$ the dual pacemaker implantation related complication rate in patients who are 65 years old or above was shown to be $6.1 \%$, which was not higher than younger patients who received dual or single chamber pacemaker therapy. Of these patients, only $4.4 \%$ required a repeated surgical procedure. Another study from Bailey and Wilkoff also reported that pacemaker and defibrillation implantation in the elderly population was not related to a significant increase in

Table 3 Distribution of complications

\begin{tabular}{llll}
\hline Complication & \multicolumn{2}{l}{ Age } & P-value \\
\cline { 2 - 3 } & $<\mathbf{7 0}$ years & $\geq \mathbf{7 0}$ years & \\
\hline Hematoma & $13(5 \%)$ & $7(2.2 \%)$ & 0.29 \\
Pocket infection & $7(2.7 \%)$ & $5(1.6 \%)$ & 0.59 \\
Pneumothorax & $2(0.8 \%)$ & $4(1.3 \%)$ & 0.72 \\
Lead dysfunction/ & $11(4.2 \%)$ & $4(1.3 \%)$ & 0.2 I \\
dislocation & & & \\
Local wound fibrosis & 0 & $3(1.0 \%)$ & $\mathrm{NA}$ \\
Free wall rupture & 0 & $\mathrm{I}(0.3 \%)$ & $\mathrm{NA}$ \\
Lead endocarditis & $6(2.3 \%)$ & 0 & $\mathrm{NA}$ \\
\hline
\end{tabular}

Abbreviation: NA, not applicable. complication rates. ${ }^{7}$ Also, even in the extreme elderly $(>80$ years) patients, the rates of implant complications were comparable to data from younger patient populations. ${ }^{12}$

The current report demonstrates that the complication rate for elderly patients who had a permanent pacemaker implantation was statistically lower than in the patients who are below the age of 70 years $(7.6 \%$ versus $15.1 \% ; P=0.005)$. As in the previous literature, ${ }^{12}$ our study showed that age does not increase the complication risk of pacemaker implantation and younger patients can be more prone to implantation related complications. This issue may be related to the higher proportion of dual chamber pacemaker implantation in younger patients and the main problem seems to be an atrial lead dislodgement.

In our study group, all complications except for pneumothorax and local wound fibrosis were encountered more in the younger patient group, such as pocket hematoma, pacemaker related infections, and lead dislodgement/ dysfunction. Although there was no difference in terms of each complication, overall the complication rate was higher in younger patients. There was only one patient with myocardial rupture and that patient was above 70 years old.

In the literature, some studies ${ }^{11-13}$ showed that none of the implantation related complications were higher in elderly patients except pneumothorax. ${ }^{11}$ Other risk factors for pneumothorax are female sex, lower body weight, lower Karnofsky score, and higher Charlson score. ${ }^{13-15}$ The Karnofsky score is used to define the performance status of the patients. ${ }^{16}$ It is reasonable that the Karnofsky score is expected to be lower as age increases. Also, higher incidence of kyphosis and lower body weight in the elderly group may contribute to increased incidence of this complication. We surmise that the hypertension did not affect the rate of complication, because the procedure was performed by venous access. Armaganijan et al described early postimplant complications (lead dislodgement or loss of capture, cardiac perforation, pneumothorax, hematoma, infection, and death) to be higher in elderly people, but late complication (lead fracture) to be the same as in young people. ${ }^{14}$ However, in a recently published large scale study, the absolute rates of postimplant complication were modest, even in nonagenarians, and the main predictor of complications was comorbidity, not age. ${ }^{15}$

\section{Conclusion}

This research shows that the current belief of higher complications for the elderly population who receive permanent pacemaker implantation is erroneous. Moreover, the patients 
who are above 70 years old may have fewer complications than the younger patients.

\section{Disclosure}

All authors report no conflict of interest in this work.

\section{References}

1. Greenspon AJ, Patel JD, Lau E, et al. Trends in permanent pacemaker implantation in the United States from 1993 to 2009: increasing complexity of patients and procedures. $\mathrm{J} \mathrm{Am} \mathrm{Coll} \mathrm{Cardiol.}$ 2012;60(16):1540-1545.

2. Coma Samartín R, Sancho-Tello de Carranza MJ, Ruiz Mateas F, et al. Sección de Estimulación Cardiaca. Spanish pacemaker registry. Eighth official report of the Spanish Society of Cardiology Working Group on Cardiac Pacing (2010). Rev Esp Cardiol. 2011;64(12):1154-1167. Spanish.

3. Mond HG, Proclemer A. The 11th world survey of cardiac pacing and implantable cardioverter-defibrillators: calendar year 2009 - a World Society of Arrhythmia's project. Pacing Clin Electrophysiol. 2011; 34(8):1013-1027.

4. Bellot P, Reynolds D. Clinical cardiac pacing, defibrillation, and resynchronization therapy. In: Ellenbogen KA, Wilkoff BL, Kay GN, Lau CP, editors. Permanent Pacemakers and Implantable Cardioverter Defibrillator Implantation. 3rd ed. Philadelphia, PA: Saunders Elsevier; 2007.

5. Worley S. Clinical cardiac pacing, defibrillation, and resynchronization therapy. In: Ellenbogen KA, Wilkoff BL, Kay GN, Lau CP, editors. Left Ventricular Lead Implantation. 3rd ed. Philadelphia, PA: Saunders Elsevier; 2007.

6. Kutalek S, Kantharia B, Maquilan M. Clinical Cardiac Pacing, Defibrillation, and Resynchronization Therapy. In: Ellenbogen KA, Wilkoff BL, Kay GN, Lau CP, editors. Approach to Generator Change. 3rd ed. Philadelphia, PA: Saunders Elsevier; 2007.
7. Bailey SM, Wilkoff BL. Complications of pacemakers and defibrillators in the elderly. Am J Geriatr Cardiol. 2006;15(2):102-107.

8. Schmidt B, Brunner M, Olschewski M, et al. Pacemaker therapy in very elderly patients: long-term survival and prognostic parameters. Am Heart J. 2003;146(5):908-913.

9. Kumar P, Kusumoto FM, Goldschlager N. Bradyarrhythmias in the elderly. Clin Geriatr Med. 2012;28(4):703-715.

10. Lim GB. Device therapy: Comorbidity is a major predictor of pacemaker safety in the elderly. Nat Rev Cardiol. Epub April 9, 2013.

11. Link MS, Estes NA 3rd, Griffin JJ, et al. Complications of dual chamber pacemaker implantation in the elderly. Pacemaker Selection in the Elderly (PASE) Investigators. $J$ Interv Card Electrophysiol. 1998;2(2):175-179.

12. Stevenson RT, Lugg D, Gray R, Hollis D, Stoner M, Williams JL. Pacemaker implantation in the extreme elderly. J Interv Card Electrophysiol. 2012;33(1):51-58.

13. Kirkfeldt RE, Johansen JB, Nohr EA, Moller M, Arnsbo P, Nielsen JC. Pneumothorax in cardiac pacing: a population-based cohort study of 28,860 Danish patients. Europace. 2012;14(8):1132-1138.

14. Armaganijan LV, Toff WD, Nielsen JC, et al. Are elderly patients at increased risk of complications following pacemaker implantation? A meta-analysis of randomized trials. Pacing Clin Electrophysiol. 2012;35(2):131-134.

15. Mandawat A, Curtis JP, Mandawat A, Njike VY, Lampert R. Safety of pacemaker implantation in nonagenarians: an analysis of the healthcare cost and utilization project-nationwide inpatient sample. Circulation. 2013;127(14):1453-1465.

16. Crooks V, Waller S, Smith T, Hahn TJ. The use of the Karnofsky Performance Scale in determining outcomes and risk in geriatric outpatients. J Gerontol. 1991;46(4):M139-M144.
Clinical Interventions in Aging

\section{Publish your work in this journal}

Clinical Interventions in Aging is an international, peer-reviewed journal focusing on evidence-based reports on the value or lack thereof of treatments intended to prevent or delay the onset of maladaptive correlates of aging in human beings. This journal is indexed on PubMed Central, MedLine, the American Chemical Society's 'Chemical Abstracts Ser-

\section{Dovepress}

vice' (CAS), Scopus and the Elsevier Bibliographic databases. The manuscript management system is completely online and includes a very quick and fair peer-review system, which is all easy to use. Visit $\mathrm{http}: / /$ www.dovepress.com/testimonials.php to read real quotes from published authors. 